\title{
Fabrication of High Performance PM Nanocrystalline Bulk AA2124
}

\author{
H.G. Salem and A.A. Sadek
}

(Submitted September 8, 2008; in revised form May 27, 2009)

\begin{abstract}
AA2124 nanopowders $<100 \mathrm{~nm}$ in particle size and $20 \mathrm{~nm}$ internal structure produced by high energy ball milling of gas-atomized micronpowders $\sim 45 \mu \mathrm{m}$ in particle size and $700 \mathrm{~nm}$ internal structure were processed in to bulk rods. The micro- and nanopowders were hot compacted using uniaxial pressing for preliminary densification at $0.7 T_{\mathrm{m}}$ of the alloy. Selected intact hot compacts (HCs) were promoted for warm severe plastic deformation via equal channel angular pressing (ECAP) at the minimum possible deforming temperature for final densification. Effect of the fabrication method of the consolidated powders was investigated. A combined processing via HC/ECAP produced bulk nanostructured rods $2.5 \mu \mathrm{m}$ and 50-60 $\mathrm{nm}$ in grain size for the micro- and nanopowder consolidates, respectively. The powder properties controlled the degree of densification and mechanical behavior during the hot compaction stage, which influenced strongly the deformation behavior during subsequent ECAP. At the end of HC/ECAP one pass, the HC stage was responsible for about 83 and $95 \%$ of the total grain coarsening encountered for the microand nanopowder HCs, respectively. Throughout the various consolidation stages employed, the ball-milled (BM) nanopowder consolidates exhibited $2 / 3$ the grain growth and displayed almost twice the hardness and compressive strength values of the gas-atomized micronpowder ones. Influence of $\mathrm{BM}$ and $\mathrm{HC}$ on the $\mathrm{Al}_{2} \mathrm{O}_{3}$ layer formed around the individual powder particles was also investigated.
\end{abstract}

Keywords Ball-milled nanopowders, consolidation behavior, gas-atomized micronpowders, hot compaction, warm ECAP

\section{Introduction}

Producing ultra-fine grain (UFG)-structured materials has become one of the most important demands since they provide enhanced mechanical properties as well as improved strengthto-weight ratio. Among the various processes used for manufacturing materials is the powder metallurgy (PM) technique, which gained a high reputation in terms of controlled material properties following a precise control of the microstructure (Ref 1-3). Great efforts were made to process nanocrystalline (NC) materials aiming for enhanced performance and serviceability. One of the major challenges is to retain the initial nanoscale structure throughout the various stages of processing, especially for the consolidation of powders during sintering (Ref 4-8).

Submicron-grained materials can be produced by intense plastic straining techniques such as equal channel angular pressing (ECAP) (Ref 9) and accumulative roll bonding (ARB) (Ref 10). Although both techniques produce uniform properties, they are incapable of producing NC structures $<200 \mathrm{~nm}$, even by deforming equivalent strains up to 5 . Successful trials

H.G. Salem and A.A. Sadek, Department of Mechanical Engineering, Youssef Jameel Science and Technology Research Center, American University in Cairo, Cairo, Egypt. Contact e-mail: hgsalem@auc egypt.edu. employing ECAP for the consolidation of powders were reported (Ref 11-14).

One of the intense plastic deformation techniques that is effective in the refinement of micronpowders into nanopowders with ultrafine NC grains is ball milling (BM) (Ref 15, 16). BM is classified as a nonhomogeneous deformation process that produces highly energetic NC powders $<50 \mathrm{~nm}$ in size. PM process starting from $<50 \mathrm{~nm}$ size into bulk products using conventional consolidation methods (hot compaction with or without subsequent conventional deformation or hot isostatic pressing), which lose their nanoscale structure; especially during subsequent processing stages that require heating for consolidation of the powder particles to produce intact fully dense products.

Although BM was mainly known for mechanical alloying, several researchers reported refinement in particle and

\begin{tabular}{|ll|}
\hline & \multicolumn{1}{c|}{ List of Abbreviations } \\
\hline HC & hot compact \\
ECAP & equal channel angular pressing \\
BM & ball milling \\
$T_{\mathrm{m}}$ & melting temperature \\
UFG & ultra fine grain \\
PM & powder metallurgy \\
NC & nanocrystalline \\
ARB & accumulative roll bonding \\
$h / d$ & height-to-diameter ratio \\
FE-SEM & field emission scanning electron microscope \\
EDX & energy dispersive x-ray \\
TEM & transmission electron microscope \\
VHN & Vickers hardness number \\
OM & optical microscope \\
\hline
\end{tabular}


crystallite size to the nanoscale level with milling time (Ref 5, 17). A successful PM component is the one produced with high density distribution, uniform internal structure, and hence uniform mechanical properties. Accordingly, the demand for ultrafine $\mathrm{NC}$ structural product with uniform superior properties triggered this research study. NC nanopowders $20 \mathrm{~nm}$ in grain size fabricated via $36 \mathrm{~h} \mathrm{BM}$ of AA2124 micronpowder $700 \mathrm{~nm}$ in grain size was processed into bulk rods through a combination of hot compaction and warm intense plastic straining via ECAP. Effect of the powder's initial properties and hot compaction parameters as a primary consolidation step, followed by ECAP one-pass and two-pass route (A) as a secondary consolidation step were investigated.

\section{Processing and Experimental Procedure}

Gas-atomized micronpowder of AA2124 with a chemical composition of Al-3.9 $\mathrm{Cu}-1.5 \mathrm{Mg}-0.65 \mathrm{Mn}-0.1 \mathrm{Si}-0.1$ was milled for $36 \mathrm{~h}$ in a high energy ball mill at $500 \mathrm{rpm}$ using a FRITCH high energy BM with ball-to-powder ratio of 30:1 to produce the nanocrystalline nanopowder used in this study. A milling time of $36 \mathrm{~h}$ under such high energy of milling was capable of the refinement of the micronpowders down to the nanoscale level without the use of liquid nitrogen. Details for the milling parameters, powder morphology, and XRD as a function of milling time were presented in another publication (Ref 18). The micronpowder had a particle size of $45 \mu \mathrm{m}$ and grain size of about $700 \mathrm{~nm}$. The BM nanopowder was formed from clusters of $300 \mathrm{~nm}$ in size with fine particles with $20 \mathrm{~nm}$ internal structure in average size. Figure 1 shows a scanning electron microscopic image for the gas-atomized powder (a) compared to the 36-h milled powders (b) at low and high magnifications.

The nanopowders were first hot compacted using singlesided uniaxial pressure in a confined die of diameter $12.7 \mathrm{~mm}$ and height of $52 \mathrm{~mm}$, which produced compacts of a height-todiameter $(h / d)$ ratio of 4.0 . The high $h / d$ ratio was selected to produce rods long enough for subsequent ECAP. Hot compaction of the nanopowders was carried out under combinations of temperatures of 360,420 , and $480{ }^{\circ} \mathrm{C}$; durations of 60 and $90 \mathrm{~min}$; pressures of 450, 525, and $600 \mathrm{MPa}$. All HCs were cooled down to $30{ }^{\circ} \mathrm{C}$ using water quenching. Only intact $\mathrm{HCs}$ were selected for further processing via ECAP single pass and second pass route (A). Results produced for the nanopowder compaction were compared to micronpowder $\mathrm{HCs}$ (450 $\mathrm{MPa}$, $480{ }^{\circ} \mathrm{C}, 60 \mathrm{~min}$ ) based on best processing conditions that produced the highest relative density, density uniformity, hardness, and compressive strength. Hot compaction consolidation maps for the AA2124 gas-atomized micronpowder are presented in another publication (Ref 19).

ECAP billets were prepared by inserting the resulting HCs in AA2024 cans of 22.8-mm diameter and $80-\mathrm{mm}$ length. The selected canning material was based on series of analysis using pure $\mathrm{Cu}$, pure $\mathrm{Al}$, and AA2024 cans to select the most suitable canning material for the powder of concern (Ref 20). The machined cans were over aged for $3 \mathrm{~h}$ at $400{ }^{\circ} \mathrm{C}$, and cooled in furnace. During ECAP, the canned HCs were pressed through a die of two equally sized channels $23 \mathrm{~mm}$ in diameter intersecting at an angle $\phi$ of $90^{\circ}$. Pressing was performed at a ram velocity of $2 \mathrm{~mm} / \mathrm{min}$ and temperature of 235 and $245^{\circ} \mathrm{C}$ on a 500-tons capacity MTS universal testing machine for the microand nanopowder HCs, respectively. Schematic drawings showing details for the can design and the ECAP die were detailed in another study by Salem and Shamma (Ref 20).

A Leica optical microscope and LEO Supra55 field emission scanning electron microscope (FE-SEM) were used for microstructural characterization at the mid plane along the longitudinal direction of the pressed rods (Ref 20). Energy dispersive spectroscopy (EDX) attached to the FE-SEM was used to identify the $\mathrm{Al}_{2} \mathrm{O}_{3}$ particles and despersoids formed within the Al-matrix. A $300 \mathrm{kV}$ Joel 2010 transmission electron microscope (TEM) was employed for the imaging of the nanoscale structure and the dislocation activity developed as a function of the various stages of processing. Linear intercept technique was employed to measure the bimodal structure produced within the consolidated powder particles after $\mathrm{HC}$ and ECAP. The OM, FE-SEM, and TEM were used for the grain size measurements of the as-received micronpowder consolidates while FE-FE-SEM and TEM were used for the nanopowder consolidates. Density of the HCs and ECA-pressed consolidates was measured using the digital Mettler-Toledo densitometer and Xylene as an auxiliary liquid. Density uniformity across the height of the consolidated rods was characterized by measuring the variation in relative density as a function of distance away from the compression head for the $\mathrm{HC}$, and along the length of the rod for the ECAP ones. The measured slop was a direct measure for the extent of density uniformity produced before and after ECAP (Fig. 2). Hardness of the HCs before and after ECAP was measured using a Mitutoyo VMH 810 microhardness tester. Vickers hardness number (VHN) values were measured

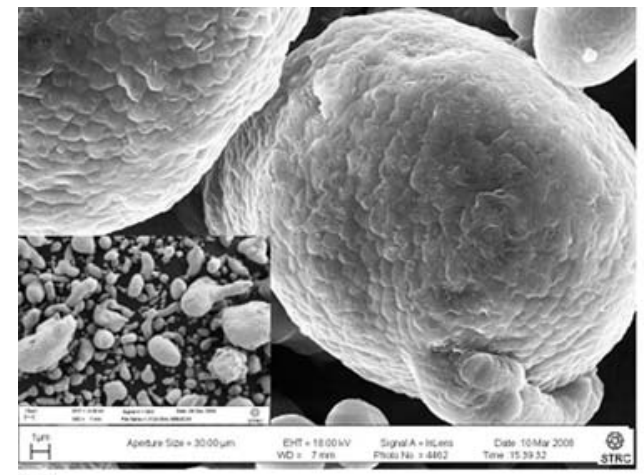

(a)

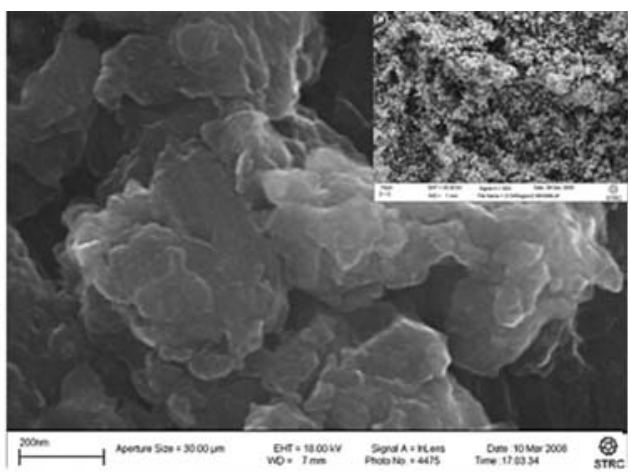

(b)

Fig. 1 FE-SEM images for the AA2124 (a) gas-atomized micronpowder and (b) 36-h milled nanopowder 
at 200gf and 15-s dwell time. Hardness measurement and microstructural imaging were conducted on longitudinal surfaces cut parallel to the compaction loading for the HCs and the flow direction for the ECAP rods. Compression testing was conducted on MTS 810 universal testing machine. For each compact, measurements were taken at the top, middle, and bottom sections in the transverse direction. Results for density, VHN, compressive properties, and grain size were based on averaged values for a minimum of three specimens per compaction condition and powder type.

\section{Results and Discussion}

The product of each process was subjected to physical, mechanical, and microstructural investigation. Through this section, the results obtained for the HCs and ECA-pressed consolidates were analyzed aiming for the production of high quality consolidates. Accordingly, the level of densification was investigated. Hardness and compressive strength of each product for the HCs and ECAP rods were investigated. Finally, microstructural analysis provided the necessary explanation for the consolidation and mechanical behavior of the produced bulk rods as well as an evidence for the influence of the combined HC/ECAP processing on the developed structure, and hence the exhibited mechanical properties.

\subsection{Hot Compaction}

3.1.1 Relative Density. Only compaction conditions (525 MPa, $480{ }^{\circ} \mathrm{C}, 90 \mathrm{~min}$ ) and $\left(600 \mathrm{MPa}, 480{ }^{\circ} \mathrm{C}, 60 \mathrm{~min}\right.$ ) produced intact and crack-free nanopowder HCs. Other

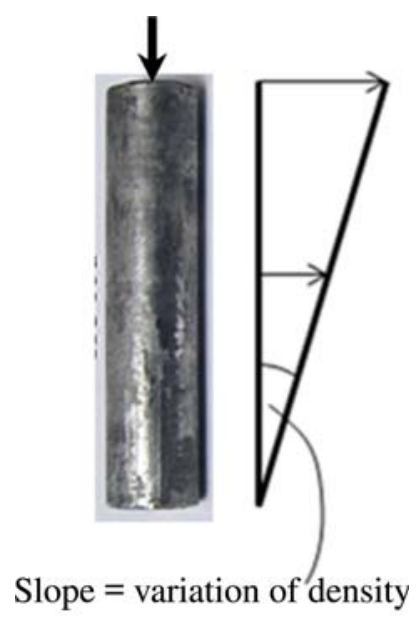

Fig. 2 An image showing the density uniformity measurement combinations of compaction conditions were incapable of producing dense enough rods suitable for subsequent processing via ECAP. Consolidation maps based on the measured density and hardness as a function of the compaction parameters were presented in the study of Sadek and Salem (Ref 19) for both powders. Table 1 lists the physical and mechanical properties measured for the selected HCs compared to the results produced for the as-received gas-atomized micronpowder hot compacted at $450 \mathrm{MPa}, 480{ }^{\circ} \mathrm{C}, 60 \mathrm{~min}$. Based on previous study (Ref 19), the pressures suitable for producing an intact compact rod with the highest densification was $450 \mathrm{MPa}$ for the micronpowders compared to 525 and $600 \mathrm{MPa}$ for the 36-h BM nanopowders. This is attributed to the strain hardening induced by high energy BM, which produced ultrafine NC nanopowders with high stored energy as presented in previous study by Salem et al. (Ref 18). From the displayed results, it is clear that the synthesis method used for the fabrication of the powder has not only influenced the consolidation behavior of the HCs, but also the produced physical and mechanical properties of the bulk product. The as-received gasatomized micronpowder produced a relative density value that is almost equivalent to the ingot metallurgy one, while lower degrees of densification were produced for the nanopowder HCs. It is suggested that the strain hardening associated with 36-h high energy milling produced nanopowders with high resistance to plastic deformation, but retarded densification. On the other hand, the relative softness of the gas-atomized powders facilitated deformation of the individual particles under the applied pressure and temperature, which enhanced densification.

3.1.2 Mechanical Properties. The nanopowder HCs exhibited 42 and $63 \%$ increase in VHN values and compressive yield strength, respectively, compared to the micronpowder one. For the nanopowder HCs, the compressive yield strength measured for both conditions was directly proportional to the relative density, which did not apply for the measured hardness. High compaction pressure over short durations of $60 \mathrm{~min}$ produced nanopowder HCs with higher hardness, while lower pressures over longer durations of $90 \mathrm{~min}$ produced lower hardness.

Figure 3 shows representative stress-strain curves for the compressive behavior of the micronpowder $\left(450 \mathrm{MPa}, 480{ }^{\circ} \mathrm{C}\right.$, $60 \mathrm{~min})$ and nano $\left(600 \mathrm{MPa}, 480{ }^{\circ} \mathrm{C}, 60 \mathrm{~min}\right) \mathrm{HCs}$. The $\mathrm{HC}$ micronpowders displayed much higher ductility at lower flow stresses compared to the nanopowder ones. No cracking was observed for the micronpowder HCs up to stain of $0.25 \mathrm{~mm} /$ $\mathrm{mm}$, while the nanopowder rods failed at much lower strains $(0.07 \mathrm{~mm} / \mathrm{mm})$ under compressive loading.

For the nanopowder, relatively lower compressive yield strength was recorded for the rods produced at lower compaction pressures (525 MPa) over longer durations (90 min). It is suggested that a combination of lower pressures and longer durations at $480{ }^{\circ} \mathrm{C}$ allowed for the softening of the energetic

Table 1 Physical and mechanical properties of selected HCs

\begin{tabular}{lcccc}
\hline Compaction conditions & Relative density, \% & Hardness, VHN & Compressive $\boldsymbol{\sigma}_{\mathbf{y s}}, \mathbf{M P a}$ & Grain coarsening, \% \\
\hline $525 \mathrm{MPa}, 480{ }^{\circ} \mathrm{C}, 90 \mathrm{~min}$ & 97.4 & 167.7 & 577.1 & 220 \\
$600 \mathrm{MPa}, 480^{\circ} \mathrm{C}, 60 \mathrm{~min}$ & 95.2 & 181.6 & 537.2 & $\mathbf{2 0 2 . 4}$ \\
$\mathbf{4 5 0} \mathbf{M P a}, \mathbf{4 8 0}{ }^{\circ} \mathbf{C}, \mathbf{6 0} \mathbf{m i n}$ & $\mathbf{9 9 . 2}$ & & & $\mathbf{3 1 0}$ \\
Bold entries for micropowder HCs & & & & \\
\hline
\end{tabular}


powder particles boundaries. This, in turn, facilitated particle sliding within the empty sites and promoted interparticle boundary diffusion with time. Higher densification enhanced the overall mechanical properties of the produced compacts. Although longer compaction duration enhanced the compressive strength, it resulted into lower VHN values, which could be due to dynamic recovery associated with heating for a longer time.

3.1.3 Structural Evolution. Effect of Ball Milling. To understand the effect of the milling on the consolidation behavior of the powders, green compacts were produced under the same pressures and durations used for the hot compaction. Figure 4(a) shows FE-SEM image for the gas-atomized micronpowder green compact, in which the $\mathrm{Al}_{2} \mathrm{O}_{3}$ (as identified by EDX) film decohesion under the effect of the compaction pressure is shown. Cold compaction at $450 \mathrm{MPa}$ of the micronpowders was responsible only for the oxide layer decohesion as well as minor fragmentation of the relatively thin layers as shown in Fig. 4(a).

For the milled nanopowders (Fig. 4b), the alumina films disappeared and were replaced by almost spherical particles of different sizes ranging between $100 \mathrm{~nm}$ and $2 \mu \mathrm{m}$. The relatively coarse particles were either encased by the aluminum clusters or isolated as pointed at by $A$-letter. Ultrafine dispersed particles were encased within the clusters as pointed at by $B$-letter. Other oxide particles (pointed at by $C$-letter) and AA2124 clusters were cracked as result of the $600-\mathrm{MPa}$ pressure associated with compaction. It is important to note that there is a significant degree of nonuniformity in the nanopowder cluster size as shown in Fig 4(b).

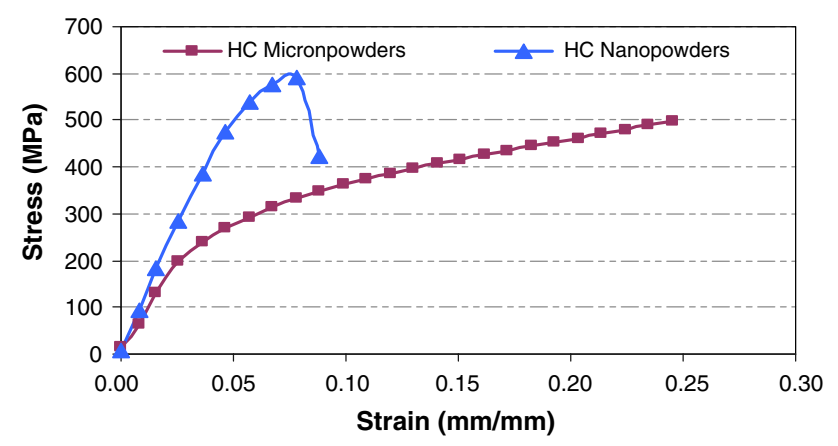

Fig. 3 Compressive behaviors for the micro- and nanopowder HCs
OM images shown in Fig. 5 represent the microstructure produced for the micro- and nanopowder HCs at low and high magnifications. Figure 5(a, b) compares both $\mathrm{HC}$ powders at low magnification. It is clear from the images that much finer structure was produced for the nanopowder compacts (Fig. 5b) compared to the micronpowder one (Fig. 5a). The oxide dark particles distributed at triple points between the consolidated particles were observed in both compacts, however, with different morphologies (size, shape, and distribution). Higher magnification images for the $\mathrm{HC}$ micronpowders (Fig. 5c) revealed the fragmentation and segregation of nonuniform coarse particles $\geq 6 \mu \mathrm{m}$ at triple points within the AA2124 matrix of the $\mathrm{HC}$ micronpowders, while other regions showed complete consolidation with thin smooth boundaries in between. Figure 5(d), on the other hand, revealed the formation of spherical particles $\leq 2 \mu \mathrm{m}$ in size uniformly distributed within the matrix of the heavily strained and consolidated nanopowder particles. Based on the study done by Karaman et al. (Ref 4), the broken surface oxide layer has a negative effect on the final ductility level if they were not refined enough, while nanosized oxide particles could enhance the thermal stability of a consolidated Al-powder during hot deformation without causing deterioration in the ductility.

Effect of Compaction Duration. Figure 6(a, b) shows HR-SEM images for the two conditions of $480{ }^{\circ} \mathrm{C} \mathrm{HC}$ nanopowders at $525 \mathrm{MPa}, 90 \mathrm{~min}$ and $600 \mathrm{MPa}, 60 \mathrm{~min}$, respectively. It is observed that compaction over shorter durations of $60 \mathrm{~min}$ did not allow for complete consolidation of some of the clustered nanoparticles as pointed at by arrows in Fig. 6(b); although higher pressures were employed. Accordingly, compaction over longer heating durations promoted higher relative density, and hence higher compressive strength (Table 1). Conversely, the relative softness of the micronpowder HCs under compression loading could have closed most of the interparticles' open spaces, which resulted in higher ductility. The compressive ductility is directly proportional to the produced degree of densification. Since the fine dispersion of the oxides exists in both nanopowder compaction conditions, it is suggested that the a shorter compaction durations of $60 \mathrm{~min}$ produced lower \% grain coarsening, which influenced the measured VHN values as shown in Table 1.

Percent Grain Coarsening. Table 1 also shows that hot compaction of the micro- and nanopowders resulted in grain coarsening of the initial powders' grain size (700 and $20 \mathrm{~nm}$,
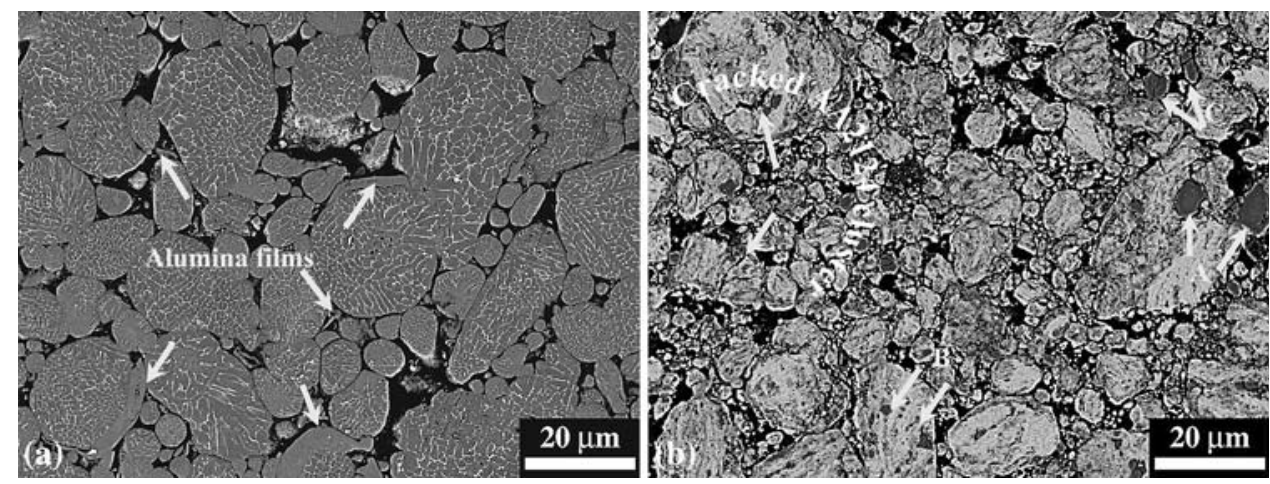

Fig. 4 FE-SEM images for the (a) micro- and (b) nanopowder green compacts showing the distribution of the $\mathrm{Al}_{2} \mathrm{O}_{3}$ within the compact rods 


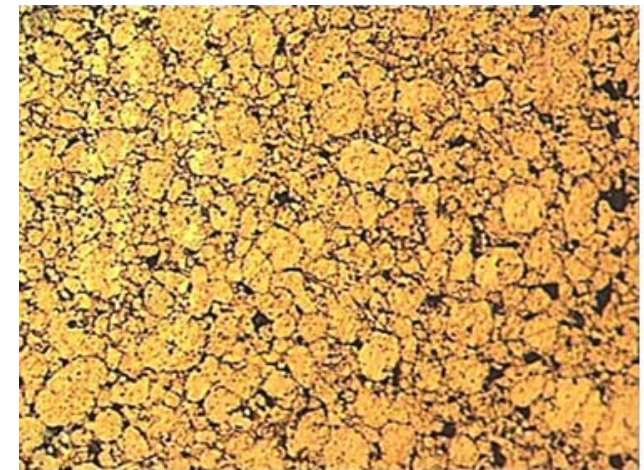

(a)

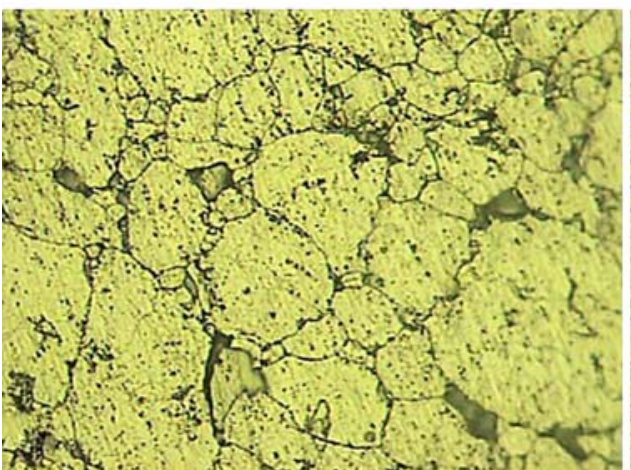

(c)

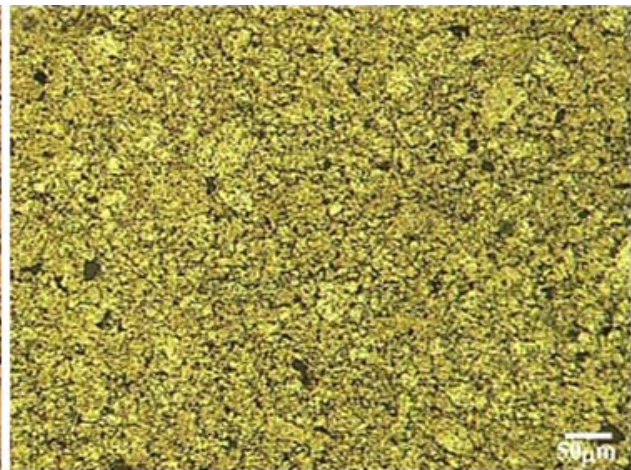

(b)

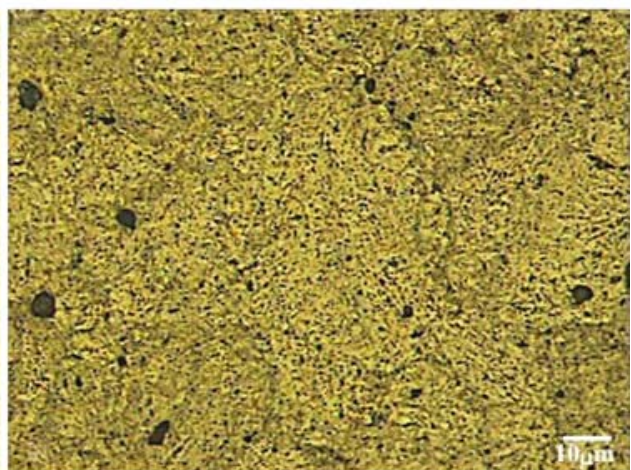

(d)

Fig. $5 \mathrm{OM}$ for $\mathrm{HCs}$ at $480{ }^{\circ} \mathrm{C}$ for $60 \mathrm{~min}$ for (a, c) micronpowder at $400 \mathrm{MPa}$ and (b, d) nanopowder at $600 \mathrm{MPa}$ at low and high magnifications, respectively

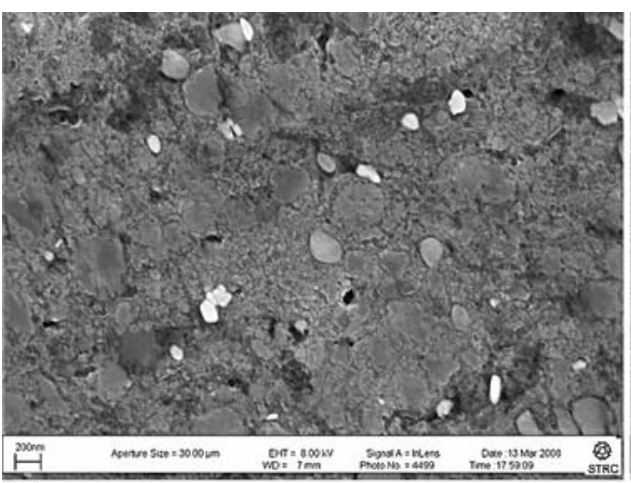

(a)

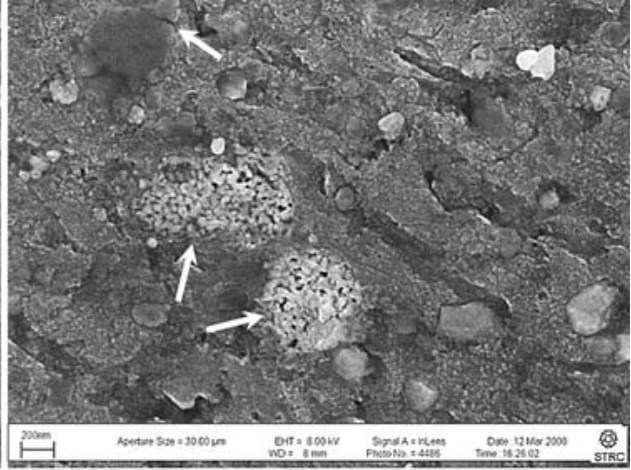

(b)

Fig. 6 FE-SEM for nanopowder $480{ }^{\circ} \mathrm{C} \mathrm{HCs} \mathrm{at} \mathrm{(a)} 525 \mathrm{MPa}, 90 \mathrm{~min}$ and (b) $600 \mathrm{MPa}, 60 \mathrm{~min}$

respectively); although, the effect was much lower for the nanopowder compacts. An average grain size of $2.2 \mu \mathrm{m}$ and $42 \mathrm{~nm}$ were measured for the micro- and nanopowder HCs, respectively. It is suggested that the uniform fine oxide particles dispersion within the BM consolidated nanopowder $\mathrm{HCs}$ partially pinned grain boundary diffusion, and hence produced lower $\%$ grain coarsening compared to that produced in the micronpowders.

\subsection{Processing Via ECAP}

The macroscopic assessment or visual inspection of the HCs after the ECAP is a basic test employed to investigate the existence of cracks or voids generated during processing. Such cracks appear in the ECAP consolidates either due to opening of inherent defects in the $\mathrm{HC}$ or due to shear localization induced by poor lubrication and/or low forming temperature (Ref 13, 20, 21). The uniform plastic deformation via ECAP one-pass and two-pass route (A) were conducted at 235 and $245^{\circ} \mathrm{C}$, for the micro- and nanopowder $\mathrm{HCs}$, respectively. Figure 7(a-d) shows the produced nanopowder consolidates after ECAP one-pass and two-pass route (A) for both hot compaction conditions. After the first pass, the measured inclination angles were $\sim 30^{\circ}$ (Fig. $7 \mathrm{a}, \mathrm{c}$ ). This disagrees with the theoretical angle $\left(45^{\circ}\right)($ Ref 13). This implies that the ECApressed consolidates experienced a lower degree of shear straining compared to the theoretically anticipated values. The observed lower angles of inclination have been explained by 


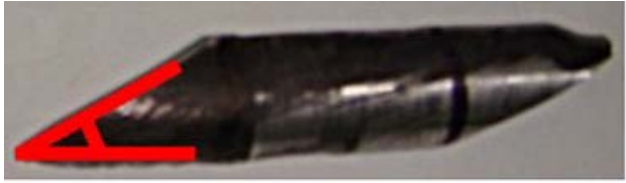

(a)

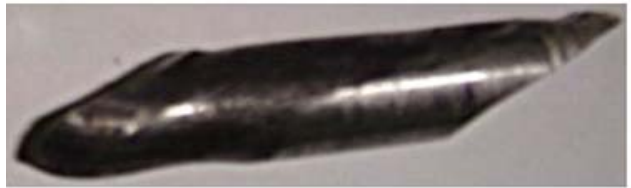

(c)

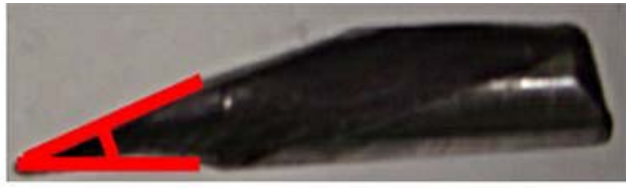

(b)

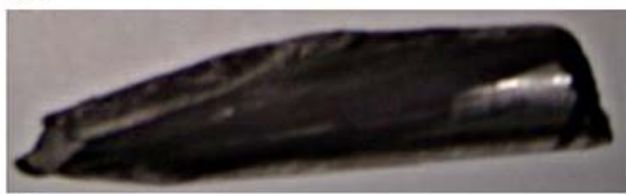

(d)

Fig. 7 Macrographs showing the nanopowder HCs after ECAP one- and two-pass route A (a, b) $525 \mathrm{MPa}, 480{ }^{\circ} \mathrm{C}, 90 \mathrm{~min}$ and (c, d) $600 \mathrm{MPa}, 480{ }^{\circ} \mathrm{C}, 60 \mathrm{~min}$, respectively

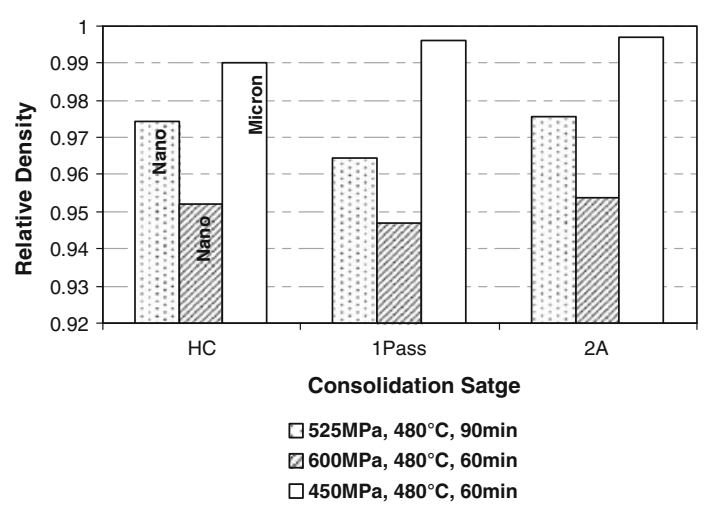

Fig. 8 Comparison of relative density values of micro- and nanopowder HCs post ECAP one- and two-pass routes (A)

Khodary et al. (Ref 21) who attributed this behavior to the powder particles rotation when densification is initially incomplete. A similar observation applies to the second pass where the measured angles were $\sim 16^{\circ}$ versus a $27^{\circ}$ theoretical angle as shown in Fig. 7(b, d). ECAP one-pass and two-pass of the micronpowder $\mathrm{HC}$ produced higher angles of inclination of $\sim 40^{\circ}$ and $\sim 22^{\circ}$ compared to the nano-ones after one- and twopass ECAP, respectively.

3.2.1 Relative Density. Figure 8 shows the relative densities produced for the micronpowder HCs before and after ECAP compared to the nanopowder ones. The relative density of the nanopowder rods dropped by about $1 \%$ after processing via one-pass ECAP, which was followed by a slight increase after two-pass route (A). Conversely, ECAP one-pass and twopass routes enhanced the density of the micronpowder HCs. For the nanopowder HCs, the drop in density after the first pass was explained by the partial consolidation of the powder particles by prior compaction that was induced by the particle resistance to plastic deformation. Hence, a partial rigid body rotation at the shear plane took place instead of being fully strained (Ref 21). This agrees with the measured lower shear angles produced after the first pass deformation (Fig. 7a). During the second pass, the nanopowder HCs had already been subjected to an additional heating cycle at $245^{\circ} \mathrm{C}$. This could have resulted in strain softening of the hardened powder particles, and hence enhanced the consolidation and overall densification (Ref 13). For the micronpowder HCs, higher levels of densification induced by prior compaction in addition
Table 2 Density variation across the consolidate length for the nano- and micropowder HCs before and after ECAP

\begin{tabular}{|c|c|c|c|c|}
\hline \multirow[b]{2}{*}{$\begin{array}{l}\text { Compaction } \\
\text { conditions }\end{array}$} & \multirow{2}{*}{$\begin{array}{c}\text { HC } \\
\text { average } \\
\text { slopes }\end{array}$} & \multicolumn{2}{|c|}{ ECAP } & \multirow[b]{2}{*}{$\begin{array}{c}\text { Improvement, } \\
\%\end{array}$} \\
\hline & & $\begin{array}{l}\text { Processing } \\
\text { route }\end{array}$ & $\begin{array}{l}\text { Average } \\
\text { slopes }\end{array}$ & \\
\hline \multirow{2}{*}{$\begin{array}{l}525 \mathrm{MPa}, 480{ }^{\circ} \mathrm{C}, \\
90 \mathrm{~min}\end{array}$} & \multirow[t]{2}{*}{0.01} & 1-Pass & 0.0028 & 357 \\
\hline & & 2-Pass (A) & 0.0013 & 769 \\
\hline \multirow{2}{*}{$\begin{array}{l}600 \mathrm{MPa}, 480{ }^{\circ} \mathrm{C}, \\
60 \mathrm{~min}\end{array}$} & \multirow[t]{2}{*}{0.012} & 1-Pass & 0.005 & 240 \\
\hline & & 2-Pass (A) & 0.0025 & 480 \\
\hline \multirow{2}{*}{$\begin{array}{l}450 \mathrm{MPa}, 480 \\
{ }^{\circ} \mathrm{C}, 60 \mathrm{~min}\end{array}$} & \multirow[t]{2}{*}{0.002} & 1-Pass & 0.0007 & 286 \\
\hline & & 2-Pass (A) & 0.0005 & 400 \\
\hline
\end{tabular}

Bold entries for micropowder HCs

to the relative softness of the consolidates facilitated the utilization of the shear strain at the intersecting channels and promoted closing of the existing scattered voids with increasing number of passes.

Table 2 lists the average slopes of the density distribution across the nanopowder HCs before and after ECAP one-pass and two-pass route (A) compared to that of the micronpowder ones. In general, processing via ECAP significantly improved the density uniformity along the $\mathrm{HC}$ length. Comparing the slopes of density produced for the nanopowder HCs before and after ECAP across the HCs length revealed the enhancement in density uniformity across the rod length after the first pass, while the density uniformity was doubled after the second pass. It is observed that the higher the degree of uniformity in density produced by prior hot compaction, the higher the enhancement by ECAP. This was clearly depicted by the effect of ECAP on the density uniformity produced for the micronpowder HCs compared to the nano-one. This could be explained by the various sources of nonlinearity during the processing of the nanopowder HCs.

3.2.2 Mechanical Properties. The VHN values for the ECA-pressed consolidates after one- and two-pass for the micro- and nanopowder HCs are shown in Fig. 9. For the nanopowder $\mathrm{HCs}$, processing via ECAP one-pass resulted in a drop in hardness by about 5\% compared to that of the HCs. After the second pass, the hardness experienced another drop of about $8 \%$ compared to that produced by the first pass. The drop in hardness after each ECAP pass reflected the dominant effect 


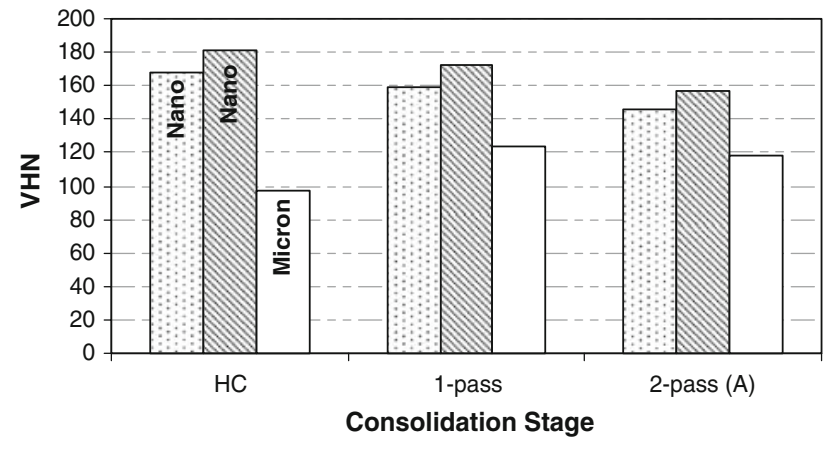

๑525MPa, $480^{\circ} \mathrm{C}, 90 \mathrm{~min}$ Q $600 \mathrm{MPa}, 480^{\circ} \mathrm{C}, 60 \mathrm{~min}$ $\square 450 \mathrm{MPa}, 480^{\circ} \mathrm{C}, 60 \mathrm{~min}$

Fig. 9 Comparison of relative density values of micro- and nanopowder HCs before and after ECAP one- and two-pass routes (A)

of strain softening over strain hardening that is induced by heating during ECAP. The energetic condition of the milled powder particles most probably resulted in a higher tendency of the structure for dynamic recovery during ECAP. The $600 \mathrm{MPa}, 480{ }^{\circ} \mathrm{C}, 60-\mathrm{min}$ consolidates maintained higher hardness values than that of the corresponding 525-MPa, $480{ }^{\circ} \mathrm{C}, 90$-min ones. The obtained results disagree with the results recorded for ECAP of ingot AA2124 billets as a function of passes, where strain hardening took place resulting in higher hardness values (Ref 9), especially when ECAP is conducted at ambient temperatures.

Although the micronpowder HCs displayed almost half the hardness recorded for the nanopowder HCs, the displayed hardness values after ECAP passes represent an opposite trend compared to that displayed by the nanopowder ones after one pass. For the micronpowder HC, ECAP resulted in the increase of the hardness by $26 \%$ followed by a decrease down to $20 \%$ after one-pass and two-pass, respectively. The hardness results produced agree with the findings of Murayama et al. (Ref 22) who reported results of slight drop in hardness of similar aluminum alloy after ECAP second pass (A). Yoon et al. (Ref 23) showed that the canned HCs are exposed to higher temperatures during the second extrusion, which was likely caused by the greater heat generation of the fully dense material passing through the shear zone. This might cause grain growth during multiple-pass extrusions. However, during the first pass, the powder consolidates at the shear zone which liberates less heat during deformation, which agrees with the enhanced density measured (Fig. 8) after the first pass for the micronpowder HCs. Strain hardening hence dominated the shear deformation which resulted in the improved hardness. For the nanopowder consolidates, the rigid body rotation of the powder particles during the first pass consumed a significant part of the induced shear strain which did not allow for the strain hardening to take place. Conversely, strain softening of the BM powders associated by warm deformation at $245{ }^{\circ} \mathrm{C}$ dominated the behavior, which resulted in the exhibited decrease in hardness.

Behavior of the ECA-pressed consolidates under uniaxial compression loading was investigated for the micro- and nanopowder HCs after subsequent ECAP one- and two-pass route (A). Deformation via ECAP did not change the compressive behavior initially exhibited by the corresponding

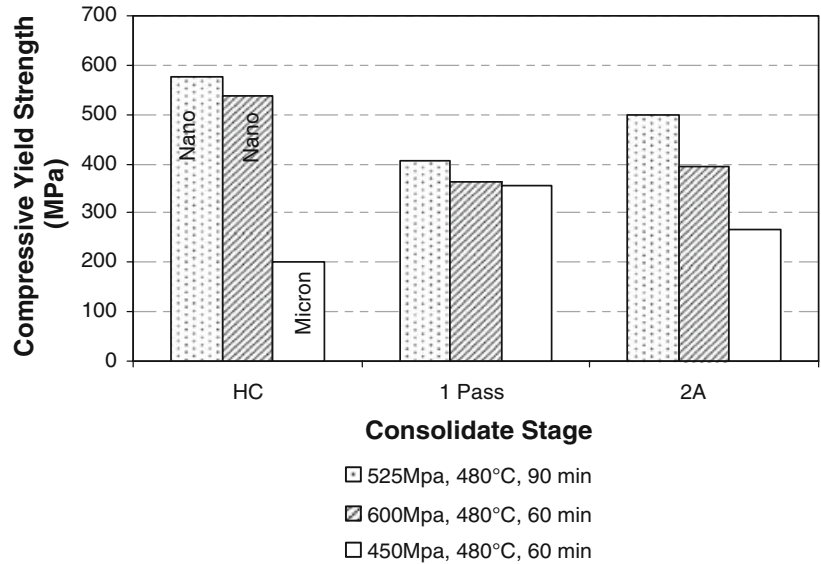

Fig. 10 Compressive yield strength of micro- and nanopowder HCs post ECAP one- and two-pass routes (A)

micro- and nanopowder HCs. This indicates that the input HC properties strongly influenced the compressive behavior of the produced consolidates during subsequent ECAP.

A comparison of the compressive yield strength of the micro- and nanopowder HCs before and after ECAP is shown in Fig. 10. The $525 \mathrm{MPa}, 480{ }^{\circ} \mathrm{C}, 90 \mathrm{~min}$ nanopowder consolidates maintained the highest compressive yield strength compared to that of the $600-\mathrm{MPa}, 480{ }^{\circ} \mathrm{C}, 60$-min consolidates after the first and second pass. For both conditions, the compressive yield strength decreased after the first pass by about $50 \%$ followed by an increase after the second pass (A) by about $26 \%$ resulting in a net lower compressive properties compared to the HC. The recorded drop in compressive yield strength after the first pass can be justified by the decrease in density recorded in Fig. 8. Compression testing is a measure of the overall mechanical properties on the macroscale; increasing porosity content affects directly the compressive behavior of the HCs, which agrees with the findings of Dobrzanski et al. (Ref 24).

The relative increase in compressive yield strength after the second pass followed the increase in density of the consolidates (Fig. 8), which was enough to increase the total strain induced by shear. These results agree with the results reported by Bing et al. (Ref 5) who proved that the compressive properties of nanostructured consolidate of Al-alloys are directly influenced by their degree of densification. It is suggested that exposure of the HCs to a second cycle of heating between and during the second pass resulted in strain softening of the strain-hardened powder particles, which facilitated the partially unconsolidated powder particles sliding and consolidation under the effect of compression and shear within the ECAP channels.

For the micronpowder $\mathrm{HCs}$, although density of the $\mathrm{HCs}$ increased with increasing the number of passes via ECAP, the compressive yield strength increased after the first pass followed by a decrease after the second pass. It is suggested that during the first pass, strain hardening dominated the deformation process and hence resulted in increasing the compressive strength, which is also supported by the recorded increase in hardness (Fig. 9). During the second pass, multiple heating cycles between the first and second pass at $235^{\circ} \mathrm{C}$ resulted in strain softening induced by either dynamic recovery or dynamic recrystallization. The results displayed by the micronpowder HCs disagree with the results reported by 
Haouaoui et al. (Ref 25) who achieved an increase in compressive yield strength by $32 \%$ after the second-pass route (A). The cause of discrepancy in results could be attributed to the difference in deformation temperatures. They conducted all the ECAP runs at room temperature where atleast one source of heat is produced at the shear zone due to the high intensity of plastic straining (Ref 19). In this research, a deformation temperature of $235^{\circ} \mathrm{C}$ was employed to conduct ECAP runs.

3.2.3 Structural Evolution. To explain the mechanical behavior displayed by the nano and micronpowder HCs as a function of ECAP passes, microstructural investigation using OM, FE-SEM, and TEM was conducted. Figure 11 shows OM images for the nanopowder $\mathrm{HCs}\left(525 \mathrm{MPa}, 480{ }^{\circ} \mathrm{C}, 90 \mathrm{~min}\right.$ (a and b) and $600 \mathrm{MPa}, 480{ }^{\circ} \mathrm{C}, 60 \mathrm{~min}$ (c and d)) compared to that produced for the micronpowder $\mathrm{HCs}\left(450 \mathrm{MPa}, 480{ }^{\circ} \mathrm{C}\right.$, $60 \mathrm{~min}$ (e and f)) after one-pass and two-pass route (A), respectively. Grains could hardly be revealed for the nanopowder HCs after ECAP (Fig. 11a-d), while the micronpowder HCs show clearly the consolidated boundaries of the initial particles that were elongated and inclined parallel to the shear direction. The internal structure is also revealed within the consolidated particles as shown in Fig. 11(e, f). From the images, densification degree was manifested in the form of voids and cavities that were scattered within the matrix. It is clear that there was a high porosity in the nanopowder HCs processed via ECAP even after the second pass, while no evidence for porosity was shown within the structure of the micronpowder HCs after one- and two-pass ECAP.

The displayed images at low magnification also show angles of inclination (represented by arrows) that varied based on the number of passes as well as the type of initial powder condition (Ref 19). The measured angles agree with those presented on the macroscale images shown in Fig. 3. Consolidates of the $525-\mathrm{MPa}, 480{ }^{\circ} \mathrm{C}, 90$-min nanopowder displayed angles of $32^{\circ}$ and $18^{\circ}$ (Fig. $11 \mathrm{a}, \mathrm{b}$ ) compared to $28^{\circ}$ and $16^{\circ}$ for those processed at $600-\mathrm{MPa}, 480^{\circ} \mathrm{C}, 60-\mathrm{min}($ Fig. $11 \mathrm{c}, \mathrm{d})$ after the

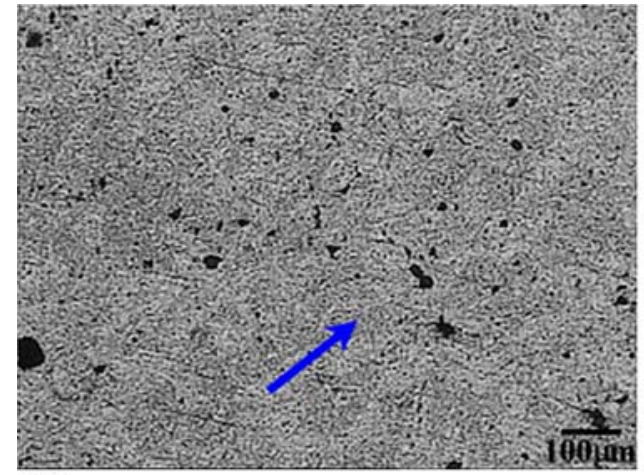

(a)

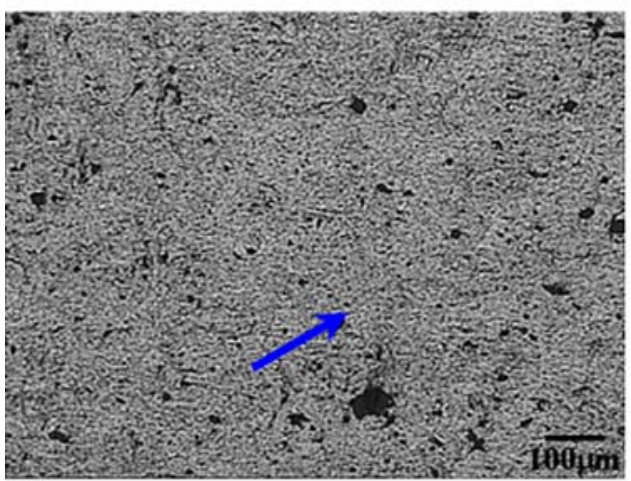

(c)

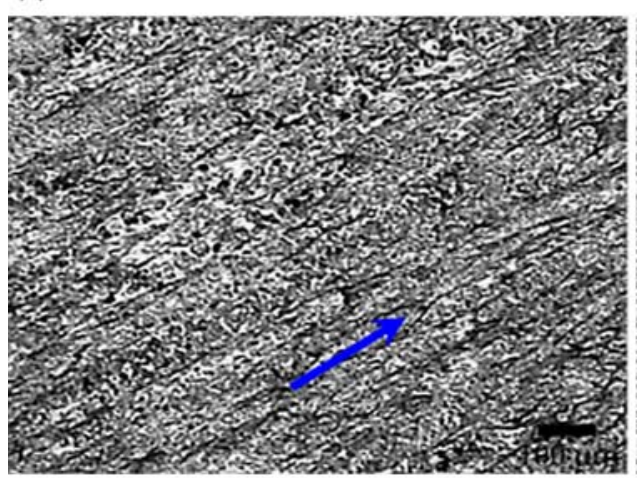

(e)

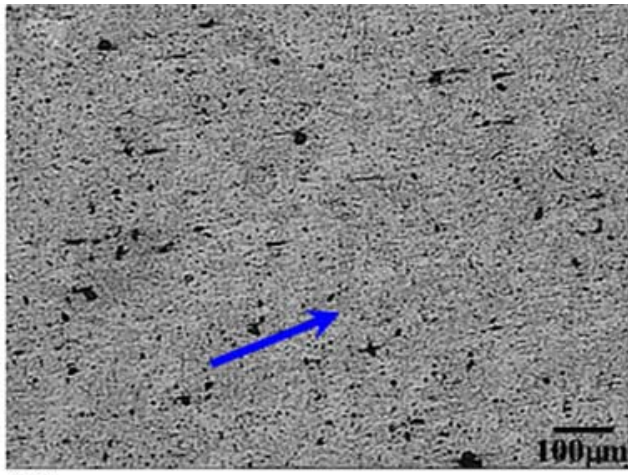

(b)

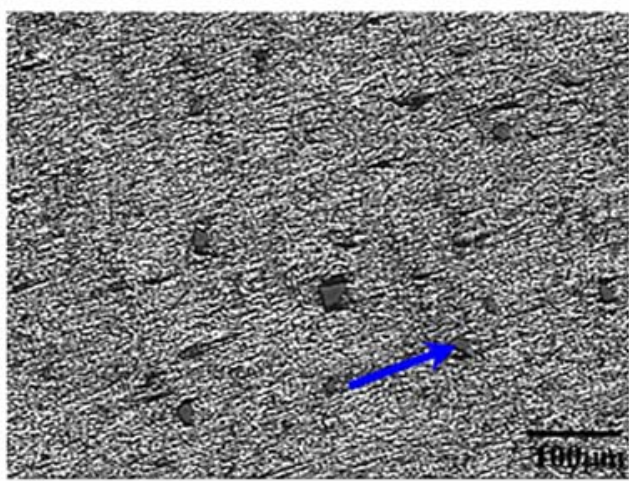

(d)

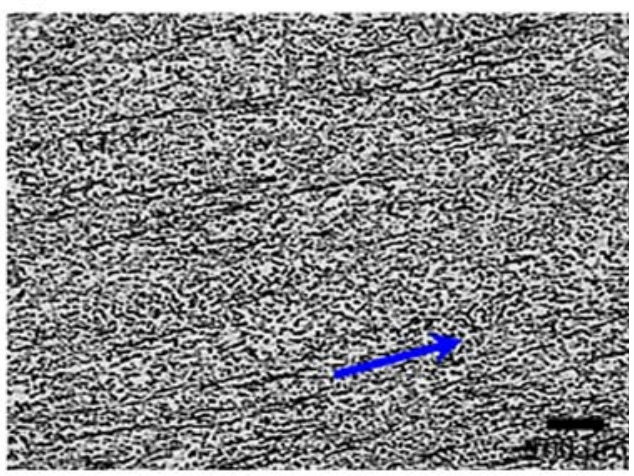

(f)

Fig. $11 \mathrm{OM}$ images of nanopowder $\mathrm{HCs}(\mathrm{a}, \mathrm{b}) 525 \mathrm{MPa}, 480^{\circ} \mathrm{C}, 90 \mathrm{~min}$ and (c, d) $600 \mathrm{MPa}, 480^{\circ} \mathrm{C}, 60$ min, and the micronpowder $\mathrm{HCs}$ after one- and two passes, respectively 
first and second passes via ECAP, respectively. Low initial density of the input compacts resulted in higher fraction of rigid body rotation of the loose or partially consolidated powder particles, hence lower inclination angles, which explains the higher inclination angles measured for the $525-\mathrm{MPa}, 480{ }^{\circ} \mathrm{C}$, 90-min nanopowder HCs (Fig. 11a, b). This also explains the high inclination angles measured for the micronpowder $\mathrm{HCs}$ $\left(\sim 40^{\circ}\right.$ and $\left.>22^{\circ}\right)$ pressed after one-pass and two-pass (A), respectively, as shown in Fig. 11(e, f). It is, therefore, suggested that the initial high density of the micronpowder $\mathrm{HC}$ promoted an efficient utilization of the shear deformation, which illustrates the recorded increase in hardness and compressive yield strength after the first pass (Fig. 9 and 10, respectively).

The TEM and FE-SEM imagings were employed in an attempt to reveal the internal structure of the micro- and nanopowder consolidates post-ECAP. Figure 12 shows FE-SEM (a, c, e, and g) and TEM (b, d, f, and h) images produced on thinned and electropolished samples for the microand nanopowder compacted at 450- and 600-MPa pressures, respectively, and $480{ }^{\circ} \mathrm{C}$ temperature for equal duration of

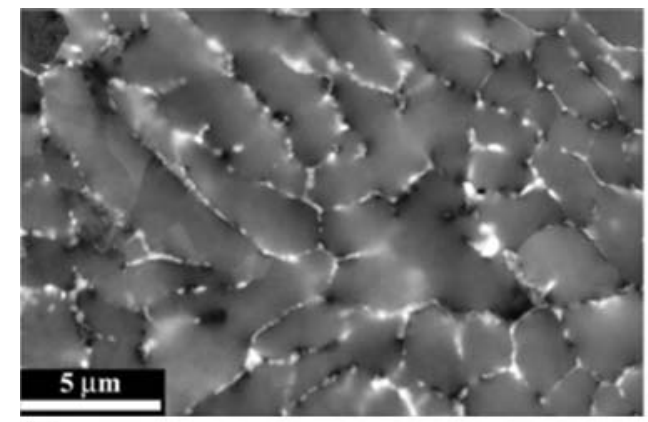

(a)

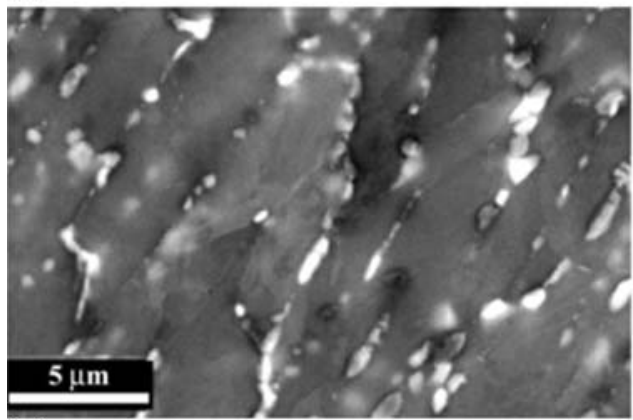

(c)

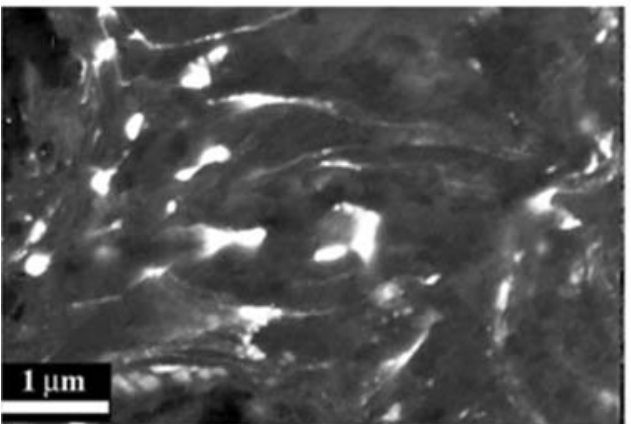

(e)

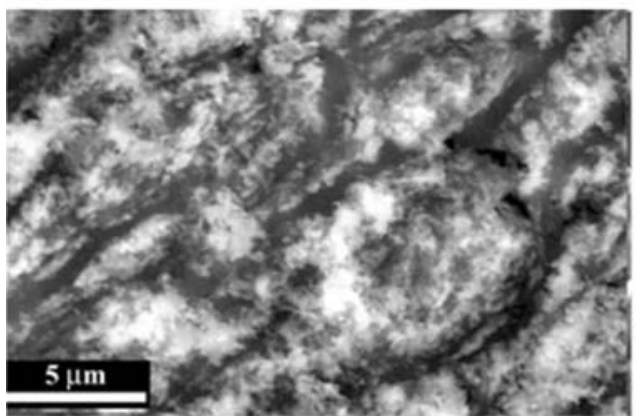

(g)

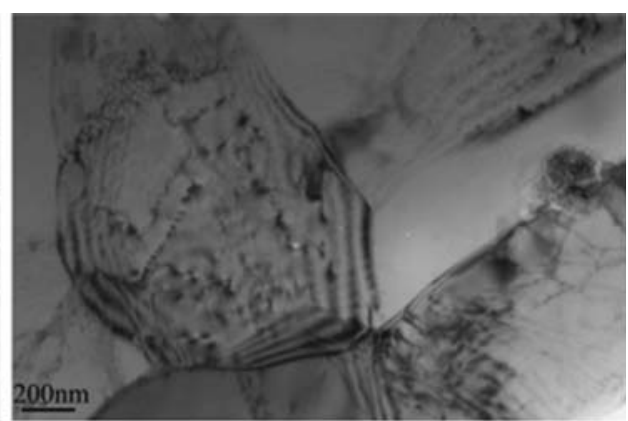

(b)

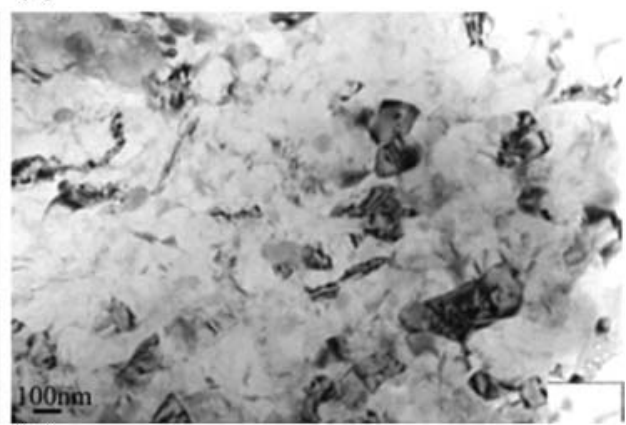

(d)

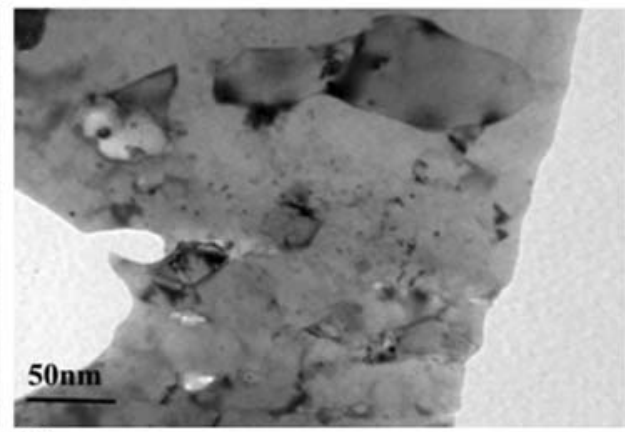

(f)

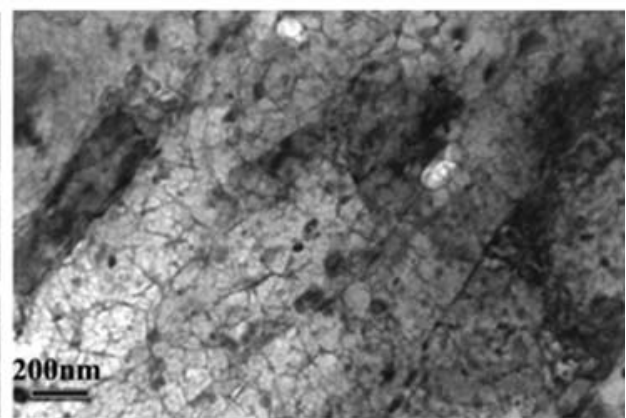

(h)

Fig. 12 FE-SEM and TEM images for the processed HCs before and after ECAP: micronpowder HC (a, b) and (c, d) one pass and nanopowder $\mathrm{HC}(\mathrm{e}, \mathrm{f})$ and $(\mathrm{g}, \mathrm{h})$ one-pass, respectively 
$60 \mathrm{~min}$ before and post-one-pass ECAP. The FE-SEM images revealed the grain structure at relatively low magnifications, while TEM imaging revealed the formation internal subgrains and/or the formation of cells within the grains at higher magnifications.

The micronpowder HCs show equiaxed grains about $2.3 \mu \mathrm{m}$ in average size (Fig. 12a), while TEM revealed dislocation activity within the grains in the form of helical dislocations and dislocation loops around very fine precipitates (Fig. 12b). The helical dislocations were formed around fine precipitates. Helical dislocations were either formed under the effect of high compaction pressures used at relatively $0.7 T_{\mathrm{m}}$, or they were formed during the quenching of the solution heat-treated structure at the end of the HC operation. A similar behavior was observed by Hassan and Gupta (Ref 26). Figure 12(c) shows FE-SEM image for the micronpowder HC post-one-pass ECAP, where shearing and alignment of the deformed grains parallel to the shear direction were revealed. A substructure $\sim 120 \mathrm{~nm}$ in average size was revealed within the sheared grains as shown in Fig. 12(d). High dislocation activity along the boundaries of the formed structure in the form of extinction contours classifies them as subgrains with low-to-medium angles of misorientation.

For the nanopowder HCs, a heavily deformed and highly distorted structure was revealed before and after ECAP (Fig. 12e and g, respectively) which made it difficult to view the internal structure. For the TEM imaging of the HCs before ECAP, the formation of equiaxed grains $<40 \mathrm{~nm}$ in average size (Fig. 12f) was revealed. While after one-pass ECAP (Fig. 11h), the sheared structure was easily depicted within domains of about $200 \mathrm{~nm}$ width, an insignificant growth in the internal structure was observed compared with that of the HC. Higher magnification images revealed evidence of high dislocation activity on the inside of the nanosized grains and at their boundaries in the form of extinction contours.

Figure 13 shows the average grain size measured for both micro- and nanopowder HCs before and after ECAP one- and two-pass. As shown in the diagram, the nanopowder HCs grain size was in tens of nanometers, while the micronpowder was in microns. The 120-nm subgrains were not considered in the data presented for the micronpowder HC. It is observed that the $525-\mathrm{MPa}, 480{ }^{\circ} \mathrm{C}, 90-\mathrm{min}$ nanopowder $\mathrm{HCs}$ experienced a slight grain coarsening ( $38 \mathrm{~nm}$ ) after the first pass followed by a significant coarsening up to a maximum of $54 \mathrm{~nm}$ after the second pass. Similar trend was produced for those of $600 \mathrm{MPa}$, $480{ }^{\circ} \mathrm{C}, 90 \mathrm{~min}$, but with a slight increase in grain size, which was attributed to a coarser initial grain size inherited by prior
HCs over longer durations. The results obtained for the nanopowder consolidates grain size post ECAP explain the higher compressive strength of after one-pass compared to the two-pass (A).

A similar behavior was also displayed by the micronpowder $\mathrm{HC}$, where the as-received powder grain size coarsened from 0.7 - to $2.0-\mu \mathrm{m}$ after $\mathrm{HC}$ followed by coarsening up to 2.5 and $3.7 \mu \mathrm{m}$ after the first and second pass ECAP, respectively. Although $62 \%$ increase in the micronpowder $\mathrm{HC}$ grain size took place after the first pass, the mechanical properties reported in Fig. 9 and 10 increased, which could be related to the dislocation activity which developed into subgrains during the first pass. This agrees with the observation made in Fig. 12(d). Another important factor that has not been the focus of this study is the interaction of the various types of secondphase particles with dislocations during sever plastic straining. Dobrzanski et al. (Ref 24) investigated the effect of various thermomechanical treatments on the second-phase particle morphology and interaction with dislocations in AA2124 ingot billets.

\subsection{Summary}

Table 3 shows a summary of the physical and mechanical properties of nanopowder HCs before and after ECAP compared to the micronpowder HCs. Although an average total coarsening of around $280 \%$ occurred via combined processing of the heavily strain hardened nanopowders HC after ECAP, the enhancement in density, density uniformity, and mechanical properties indicates the importance of employing both techniques. From Fig. 10, ECAP two-pass produced a combination of very high compressive yield strength compared to the first pass. Based on the displayed results, it is anticipated that increasing the number passes beyond two-passes could improve the consolidation, and hence enhance the product's physical and mechanical properties.

Comparing the AA2124-T851 properties with that produced for the investigated $36-\mathrm{h}$ milled nanopowder consolidates without tempering heat treatment, it is found that a hardness of 146 versus $181 \mathrm{HV}$ are produced, respectively. In addition, the processed nanopowders display compressive strength of 590-620 MPa, which can substitute for metal matrix composite of AA2124 micronpowder (75- $\mu \mathrm{m}$ particle size) reinforced with either $10 \% \mathrm{BN}$ or $15 \% \mathrm{Al}_{2} \mathrm{O}_{3}$ processed by a combined cold uniaxial compaction followed by conventional extrusion at $480{ }^{\circ} \mathrm{C}$ with an extrusion ratio of $3.25: 1(\operatorname{Ref} 25)$.

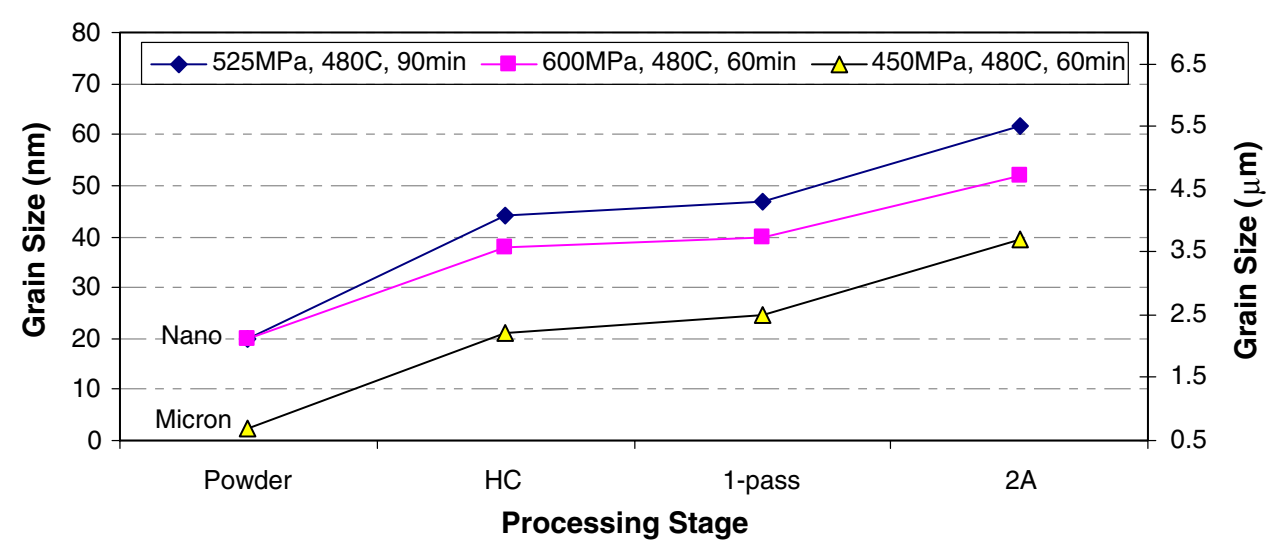

Fig. 13 Average grain size of the micro- and nanopowder HCs before and after ECAP one- and two-pass routes (A) 
Table 3 Summary for physical and mechanical properties of micro and nanopowder HCs before and after ECAP

\begin{tabular}{|c|c|c|c|c|c|}
\hline Consolidation stage & Processing stage & Relative density, \% & Hardness, VHN & $\begin{array}{c}\text { Compressive, } \\
\sigma_{\mathrm{YS}}, \mathrm{MPa}\end{array}$ & $\begin{array}{c}\text { Total grain } \\
\text { coarsening, } \%\end{array}$ \\
\hline \multirow[t]{3}{*}{$525 \mathrm{MPa}, 480{ }^{\circ} \mathrm{C}, 90 \mathrm{~min}$} & $\mathrm{HC}$ & 98.9 & 167.7 & 577.1 & 220 \\
\hline & 1 Pass & 99.5 & 158.7 & 407.4 & 235 \\
\hline & 2 Pass (A) & 99.6 & 146 & 499.3 & 307 \\
\hline \multirow[t]{3}{*}{$600 \mathrm{MPa}, 480{ }^{\circ} \mathrm{C}, 60 \mathrm{~min}$} & $\mathrm{HC}$ & 99.0 & 181.6 & 537.2 & 190 \\
\hline & 1 Pass & 99.6 & 171.9 & 385.4 & 200 \\
\hline & 2 Pass (A) & 99.7 & 157.8 & 395 & 261 \\
\hline \multirow[t]{3}{*}{$450 \mathrm{MPa}, 480{ }^{\circ} \mathrm{C}, 60 \mathrm{~min}$} & $\mathrm{HC}$ & 99.2 & 97.5 & 202.4 & 300 \\
\hline & 1 Pass & 99.6 & 123.5 & 355.6 & 362 \\
\hline & 2 Pass (A) & 99.7 & 117.7 & 265.2 & 498 \\
\hline
\end{tabular}

Comparing the percent grain coarsening listed in Table 3 before and after ECAP one- and two-pass, it is obvious that most of the grain coarsening was encountered during the $\mathrm{HC}$ stage. Warm ECAP $\left(245^{\circ} \mathrm{C}\right)$ of the nanopowder $\mathrm{HCs}$ was responsible for additional average grain growth of 12.5 and $78 \%$ after the first and second pass, respectively. However, for the micronpowder $\mathrm{HC}$, warm ECAP $\left(235^{\circ} \mathrm{C}\right)$ was responsible for additional 62 and 198\% grain growth after the first and second passes, respectively. This was expected due to the higher temperatures used for the compaction stage and the effect of high intensity of plastic deformation induced during the ECAP stage.

It was anticipated that the percent grain coarsening of the energetic BM nanopowders to be higher than the gas-atomized micro-one due to the obvious difference in stored energy associated with prior BM. Based on a previous study on the same alloy by Salem et al. (Ref 18) during the first $6 \mathrm{~h}$ of milling time, the oxide film fragmented into fine particles, and was embedded within the soft powder particles which formed flaky particles by cold welding. Increasing the BM time beyond $6 \mathrm{~h}$ results in strain hardening followed by refinement of AA2124 powder flakes to the nanoscale level. Since $\mathrm{Al}_{2} \mathrm{O}_{3}$ is classified as ceramic material, its despersoids should be stable against either solutionizing or overaging at $245{ }^{\circ} \mathrm{C}$. Accordingly, it is suggested that the refinement of the $\mathrm{Al}_{2} \mathrm{O}_{3}$ particles by the high energy milling for $36 \mathrm{~h}$ resulted not only in the dispersion strengthening effect, but also acted as stable particles that pinned grain growth during the successive heating stages employed in this study. Segregation of the fragmented coarse oxide particles in the micronpowder particles promoted grain growth of the consolidates during HC and ECAP. Accordingly, the retained strain-hardening effect associated with prior BM, the ultrafine nanograin structure, the distribution of $\mathrm{Al}_{2} \mathrm{O}_{3}$ fine particles within the Al-matrix as well as the enhanced uniform densification produced via ECAP, resulted in an overall enhancement in mechanical properties of the BM nanopowder consolidates compared to the micronpowder one.

\section{Conclusions}

(1) AA2124 nanopowder fabricated by high energy BM with an initial grain size of $20 \mathrm{~nm}$ was consolidated into bulk nanostructured rods $50-60 \mathrm{~nm}$ in grain size by a combined processing of HC and warm ECAP with uniform superior mechanical properties.

(2) Milling for $36 \mathrm{~h}$ results in the production of fine distribution of $\mathrm{Al}_{2} \mathrm{O}_{3}$ within the AA2124 Al-powder matrix through the fragmentation and refinement of the oxide film, hence pins grain growth during the $\mathrm{HC}$ and warm ECAP two-passes.

(3) The optimization process is highly important at the hot compaction stage, since the performance of the hot compact dominantly controls the produced properties of the extrudates after processing via ECAP.

(4) ECAP post $\mathrm{HC}$ enhances the density and density uniformity, which positively influences the mechanical properties of both types of powders.

(5) Although one-pass ECAP enhances the nanopowder HC consolidates' density uniformity, it results in lower density, hardness, and compressive strength compared to the $\mathrm{HC}$ due to rigid body rotation of the partially unconsolidated particle clusters inherited from prior stage of $\mathrm{HC}$.

(6) ECAP two-pass route (A) improves the compressive strength and ductility and provides an insight for improved compressive properties when multiple passes are employed.

(7) The retained strain hardening effect, associated with prior $\mathrm{BM}$, the ultrafine nanograin structure, the distribution of $\mathrm{Al}_{2} \mathrm{O}_{3}$ fine particles within the Al-matrix as well as the enhanced uniform densification produced via ECAP, results in an overall enhancement in mechanical properties of the BM nanopowder consolidates compared to the micronpowder one.

(8) Nanopowders synthesized by BM can be processed into bulk nanostructured products with superior properties for high performance applications through combined HC/ECAP two-pass route A.

\section{Acknowledgments}

The authors acknowledge the financial support of the Yousef Jameel Science and Technology Research Center (YJ-STRC) at the American University in Cairo for this research study. The authors thank Dr. M. Attallah from Manchester University for his help in conducting the TEM and FE-SEM investigations. 


\section{References}

1. K. Galanty, P. Kazanowski, P. Kansuwan, and W. Misiolek, Consolidation of Metal Powders During the Extrusion Process, J. Mater. Process. Technol., 2002, 125-126, p 491-496

2. O.N. Senkov, D.B. Miracle, J.M. Scott, and S.V. Senkova, Equal Channel Angular Extrusion Compaction of Semi-Amorphous A185Ni10Y2.5La2.5 Alloy Powder, Mater. Sci. Eng., 2003, 365, p $12-21$

3. F. Tang, T.E. Anderson, and S.B. Biner, Solid State Sintering and Consolidation of Al Powders and Al Matrix Composites, J. Light Metals, 2002, 2, p 201-214

4. J. Karaman, J. Im, S. Mathaudhu, Z. Luo, and K. Hartwig, The Effect of Temperature and Extrusion Speed on the Consolidation of Zr-Based Metallic Glass Powder Using Equal Channel Angular Extrusion, Metall. Mater. Trans. A, 2003, 34A, p 247-256

5. Q. Bing, Q. Han, and J. Lavernia, Deformation Mechanisms of Nanostructured Al-Alloys, Adv. Eng. Mater., 2005, 7(5), p 457-467

6. J. Robertson, J. Im, I. Karaman, and K. Hartwig, Consolidation of Amorphous Copper Based Powder by Equal Channel Angular Extrusion, J. Non-Crystall. Solids, 2003, 317, p 44-151

7. I. Sabirov, O. Kolednik, R. Valiev, and R. Pippan, Equal Channel Angular Pressing of Metal Matrix Composites: Effect on Particle Distribution and Fracture Toughness, Acta Mater, 2005, 53, p 4919 4930

8. K. Xia and X. Wu, Back Pressure Equal Channel Angular Consolidation of Pure Al-Particles, Scripta Mater, 2005, 53, p 1225-1229

9. H. Lin, C. Xu, B.Q. Han, E.J. Lavernia, and T.G. Langdon, An Evaluation of Cavity Development in the Tensile Testing of UltrafineGrained Iron Processed by ECAP, Ultrafine Grained Materials III, Y.T. Zhu, T.G. Langdon, R.Z. Valiev, S.L. Semiatin, D.H. Shin, and T.C. Lowe, Ed., The Minerals, Metals and Materials Society, Warrendale, PA, 2004, p 523-528

10. N. Tsuji, Y. Saito, H. Utsunomiya, and S. Tanigawa, Ultra-Fine Grained Bulk Steel Produced by Accumulative Roll-Bonding (ARB) Process, Scripta Mater, 1999, 40, p 795-800

11. S. Xiang, K. Matsuki, N. Takatsuji, M. Tokizawa, T. Yokote, and J. Kusui, Microstructure and Mechanical Properties of PM 2024 Al-3Fe$5 \mathrm{Ni}$ Alloy Consolidated by a New Process, Equal Channel Angular Pressing, J. Mater. Sci. Lett., 1997, 16, p 1725-1727

12. S. Mathaudhu, K. Hartwig, and I. Karaman, Consolidation of Blended Powders by Severe Plastic Deformation to Form Amorphous Metal Matrix Composites, J. Non-Crystall. Solids, 2007, 353(2), p 311

13. T. Langdon, The Principles of Grain Refinement in Equal-Channel Angular Pressing, J. Mater. Sci. Eng., 2007, 462(1-2), p 3-11
14. H. Hong and H. Chung, Effect of Vacuum Hot Pressing Parameters on the Tensile Properties and Microstructures of SiC-2124 Al Composites, Mater. Sci. Eng. A, 1995, 194, p 165-170

15. H. Fecht, E. Hellstren, Z. Fu, and W. Johnson, Nanocrystalline Metals Prepared by High-Energy Ball Milling, Metall. Trans., 1990, 21A, p 2333-2337

16. J. Yin, M. Umemoto, Z.G. Liu, and K. Tsuchiya, Formation Mechanism and Annealing Behavior of Nanocrystalline Ferrite in Pure Fe Fabricated by Ball Milling, ISIJ Int., 2001, 41, p 1389-1396

17. H. Sheu, L. Hsiung, and J. Sheu, Synthesis of Multiphase Intermetallic Compounds by Mechanical Alloying in Ni-Al-Ti System, J. Alloys Compd., 2009, 469, p 483-487

18. H. Salem, S. El-Eskandarany, and H. Abdul Fattah, Characterization of the Consolidation behavior of Fabricated Nanocrystalline-Nanopowders of TiC/Al-2124 Composite, ASME Multifunctional Nanocomposite Conference and Exhibition, Sep 20-22, 2006, Honolulu, Hawaii

19. A. Sadek and H. Salem, Construction of Consolidation Maps of PreECAE Hot Compact Nanocrystalline-Micron Powders, ASME 2nd Multifunctional Nanocomposites and Nanomaterials International Conference and Exhibition, Sharm El-Sheikh, Jan 11-13, 2008

20. H. Salem and M. Shamma, Effect of the Compaction Parameters and Canning material of Nanostructured Al-Powder Consolidated via Intense Plastic Straining Process, ASME 2nd Multifunctional Nanocomposites and Nanomaterials International Conference and Exhibition, Sharm El-Sheikh, Jan 11-13, 2008

21. K.I. Khodary, H.G. Salem, and M.A. Zikry, Equal Channel Angular Pressing of Canned 2124-Al Compacts: Processing, Experiments and Modeling, Metall. Mater. Trans. A, 2008, 39A, p 2184-2192

22. M. Murayama, Z. Horita, and K. Hono, Microstructure of Two-Phase Al-1.7 at $\% \mathrm{Cu}$ Alloy Deformed by Equal-Channel Angular Pressing, Acta Mater., 2001, 49, p 21-29

23. S. Yoon, S. Hong, and H. Kim, Mechanical Properties of Equal Channel Angular Pressed Powder Extrudates of a Rapidly Solidified Hypereutectic Al-20 Wt\% Si Alloy, J. Mater. Sci. Eng., 2007, 449451, p 966-970

24. L. Dobrzanski, A. Wlodarczky, and M. Adamiak, The Structure and Properties of PM Composite Materials Based on EN AW-2124 Aluminum Alloy Reinforced with the $\mathrm{BN}$ or $\mathrm{Al}_{2} \mathrm{O}_{3}$ Ceramic Particles, J. Mater. Process. Technol., 2006, 175(1-3), p 186-191

25. M. Haouaoui, I. Karaman, H. Maier, and K. Hartwig, Microstructure Evolution and Mechanical Behavior of Bulk Copper Obtained by Consolidation of Micro and Nanopowders Using Equal Channel Angular Extrusion, Metall. Mater. Trans., 2004, 35A, p 2935-2948

26. S.F. Hassan and M. Gupta, Effect of Length Scale of $\mathrm{Al}_{2} \mathrm{O}_{3}$ Particulates on Microstructural and Tensile Properties of Elemental Mg, Mat. Sci. Eng. A, 2006, 425, p 22-27 